\author{
MIROSŁAW PAWLAK \\ Uniwersytet im. Adama Mickiewicza w Poznaniu \\ Wydział Pedagogiczno-Artystyczny w Kaliszu
}

\title{
The role of in-service training for language teachers in the domain of language competence
}

\begin{abstract}
Foreign language teachers' language competence is one of the key factors contributing to the success of instruction as it ensures the provision of a good model of the target language, enables teachers to address the problems learners encounter, and makes teaching more creative. For this reason, improving this facet of a teacher's expertise is indispensible in in-service teacher training, either in the form of stand-alone courses or modules incorporated into more comprehensive teacher education programs. The main aim of the present paper is to emphasize the importance of language teachers' proficiency in the language they teach, describe its dimensions, present the possible goals of in-service teacher education in this area, and discuss issues involved in conducting and organizing training of this kind.
\end{abstract}

KEYWORDS: second language teacher education, language competence, teacher training, in-service second language teachers.

\section{INTRODUCTION}

The knowledge base of language teaching is typically conceptualized as a highly complex system which includes such components as content knowledge, pedagogical content knowledge, general pedagogic knowledge, curricular knowledge, contextual knowledge and process knowledge (cf. Roberts 1998). Although the first of these, which includes knowledge about and competence in the target language, is of pivotal importance in the sense that it is a prerequisite for language teaching as such, it is often neglected in in-service teacher training which tends to focus on the development of theoretical disciplinary knowledge and specific teaching skills. Such a situation is very unfortunate since many, if not most, foreign language teachers, work- 
ing with students of limited proficiency, having scant access to the target language on a daily basis and being too preoccupied with everyday responsibilities to devote ample time to maintaining their language competence, are bound to become deskilled to some extent and would thus surely benefit from opportunities to engage in more demanding language use. The aim of the present paper is to highlight the importance of language teachers' proficiency in the language they teach, describe its components, present the possible goals of in-service teacher education in this area, and discuss issues involved in conducting and organizing training of this kind.

\section{IMPORTANCE OF TEACHERS' PROFICIENCY}

The importance of language teachers' good command of the target language is recognized by the majority of specialists in the field of second language teacher education. In the first place, it is included among the types of knowledge and understanding, as well as strategies and skills enumerated in the European Profile for Language Teacher Education (Kelly et al. 2004), with reference to both initial and in-service training (items 16 and 27). As the developers of this landmark frame of reference emphasize, "The greater the language competence of a teacher, the more creative and confident their teaching will be (...) It is the responsibility of the teacher to ensure their language proficiency is sufficient to allow them to teach effectively and accurately" (2004: 68). A very similar view is embraced in a number of other publications on the subject, with Lafayette (1993: 135) pointing out that "Among the components of content knowledge, none is more important to foreign language teaching than language proficiency", Medgyes (2001: 440) proclaiming that "(...) the most important professional duty that non-NESTs [non-native English-speaking teachers] have to perform is to make linguistic improvements to their English", and Farrell (2007: 55) commenting that "(...) a fundamental component of a language teacher's professional competence is his or her proficiency in the language he or she teaches". Such assumptions seem to be particularly relevant in the case of in-service foreign language teachers who no longer enjoy the benefit of attending regular target language courses and whose competences and skills are bound to gradually attrite as a result of scant exposure, limited opportunities for advanced language use inside and outside the classroom, and, more often than not, overreliance on the same materials for lengthy periods of time (cf. Berry 1990).

Although much depends on the level of a particular group of students, it is obvious that lacking target language proficiency is likely to have a negative impact on numerous aspects of teaching. One area that immediately 
comes to mind is the quantity and quality of the available target language input because teachers who have limited command of the language they teach may display a proclivity to fall back upon the shared mother tongue, experience considerable difficulty in providing good language models or supplying sufficiently rich language learning input, and find it problematic to monitor their own speech and writing for accuracy as well as to offer appropriate feedback on their learners' errors. Insufficient competence also translates into lower quality of the teaching process as such. This is because practitioners are reluctant to improvise within a lesson, adapt textbooks to the objectives pursued, the characteristics and needs of the students by omitting, replacing or supplementing some of the sections (cf. Harmer 2007), or illustrate the points taught with suitable samples of authentic materials. Problems can also be expected with providing appropriate explanations and examples in the area of grammar and lexis, responding to the various questions concerning comprehension or production that students pose, accessing and using target language resources, or drawing upon new methodologies. Given such a wide range of problems, making improvement of target language proficiency one of the priorities of in-service teacher-training is likely to have a number of benefits. According to Farrell (2007), these include higher standards of use of the target language for the institution and its teachers, better learning outcomes, access to higher levels of professional development, better-quality skills for planning lessons and developing materials, personal satisfaction, and a greater choice of teaching methodologies available.

\section{DIMENSIONS OF TARGET LANGUAGE PROFICIENCY}

Before moving on to discuss the specific ways in which teachers' language proficiency can be augmented through different types of in-service teacher training, a few comments are in order on the dimensions of this kind of knowledge. A useful point of reference here is the model of communicative competence put forward by Canale and Swain (1980) and later modified by Canale (1983) which, despite being almost thirty years old, continues to be one of the most influential in discussions of what the knowledge of a second or foreign language involves. In this conceptualization, communicative competence is viewed as consisting of four components, namely (1) grammatical competence, which is connected with the knowledge of the different subsystems of the target language (i.e. grammar, vocabulary, pronunciation and spelling), (2) discourse competence, which involves the ability to compose coherent and cohesive texts in speech and writing, (3) sociolinguistic compe- 
tence, which comprises the ability to use the language appropriately in a given context and in a way that respects sociocultural rules of use, and (4) strategic competence, which involves the ability to successfully overcome impasses in communication through the employment of communication strategies. Although there might be differences in terms of the overall division, terminology and scope of specific categories, similar dimensions of target language proficiency can be found in other key models of communicative competence, notably the ones proposed by van Ek (1986) and Bachman (1990).

What should be kept in mind, however, is that having adequate competence in all these areas does not guarantee that it will be successfully applied in spontaneous communication in order to engage in the skills of comprehension, production, interaction and mediation, or some kind of combination of these in real-time processing conditions. This is closely related to the key distinction between explicit and implicit linguistic knowledge, with the former being described as conscious and declarative, and the latter being characterized as unconscious and procedural (cf. Ellis 2009). In other words, explicit knowledge of grammar rules, strategies of managing conversation or pragmatic conventions can only be useful when language users have adequate time to apply it, as is usually the case with traditional paper-andpencil tests or exercises, but it does not constitute a sufficient basis for attaining genuine communicative goals under time pressure, in which case some form of implicit knowledge is indispensable. Beyond doubt, this is an important consideration to be taken into account when designing the language module of in-service teacher training programs, as it demonstrates that the provision of large amounts of sheer knowledge about language (KAL), regardless of how broadly it might be defined, is inadequate as teachers may find it difficult to draw upon conscious knowledge of this kind in the actual act of teaching. For this reason, as Bartels emphasizes (2009: 300):

(...) SLTE [second language teacher education] courses need to stop focusing on academic practices, such as reading studies and discussing theories. Instead, SLTE courses need to provide learning experiences in which (a) L2 teachers use (or develop) KAL and local knowledge to engage in teaching-like tasks, (b) language teachers link and abstract from the knowledge acquired by participating in such activities, and (c) teachers learn to design and carry out deliberate practice activities that help them acquire the KAL that they feel they need.

The ways in which these crucial guidelines can inform the goals, methodology and design of the language component of in-service teacher education will be the concern of the subsequent section. 


\section{ISSUES IN ORGANIZING LANGUAGE TRAINING FOR IN-SERVICE TEACHERS}

When organizing a course or a program module which aims at improving the target language proficiency of in-service teachers, several fundamental issues have to be taken into account which are connected with the objectives of the training, the selection and scope of areas to be addressed, the choice of appropriate methods, techniques and resources, as well as decisions concerning organization. General goals of such training, some of which overlap with those mentioned by Farrell (2007), might include:

- developing knowledge in the area of the four competences discussed above;

- developing the ability to employ explicit knowledge in communicative tasks so that implicit knowledge can develop;

- improving proficiency in the application of all the main language skills;

- raising awareness of how the target language works;

- developing confidence in using the target language;

- developing awareness of the nature of classroom discourse;

- devising strategies for realizing the main classroom functions in the target language;

- reducing overdependence on the coursebook and teacher manual;

- improving ability for self-assessment of language use;

- fostering reflection and autonomy with respect to improving language competence.

Clearly, general goals of this kind will have to be translated into much more specific objectives when dealing with a particular group of teachers who are likely to differ widely not only with respect to their distinctive characteristics, such as the proficiency measured in terms of common reference levels, educational stage, type of institution, etc., but also their own goals, needs, perceptions and expectations. When dealing with quite homogenous groups, as would be the case with teachers working at the primary and secondary levels, for example, it could be assumed that the language proficiency of the latter has to be much higher than that of the former, concentrating to a much greater extent on the use of language for special purposes, such as that reflecting the contents of particular school subjects (cf. Kelly et al. 2004). Still, even here, let alone groups of teachers with different institutional backgrounds, there is bound to be considerable individual variation, which dictates that careful needs analysis should be undertaken, preferably prior to the initiation of the course, or, should this prove impossible, 
at its very outset. This could be done in a variety of ways, including self-assessment through the use of the common reference levels, the self-assessment grid included in a suitable version of the European Language Portfolio, or widely available online resources such as DIALANG, formal or informal surveys that can be administered in class, as well as various forms of peer-coaching which could include observation or participation in teacher development groups. At the same time, it should be emphasized that the outcomes of needs analysis can only take us thus far, for the simple reason that the participating teachers may vary to such an extent and along so many dimensions that it will be impossible to accommodate individual preferences in all cases, with the effect that some commonalities will have to be sought out and a fair amount of give-and-take will be indispensable. Therefore, it is advisable to include in language training courses both a general module, comprising the common goals to be implemented in class, and an individual module, which would be based on individualized study plans worked out in collaboration with each participant and discussed during face-to-face interactions in allotted class time.

As regards the choice of methodology, it should take into consideration the fact that the vast majority of course participants will have usually completed courses narrowly focused on pronunciation, grammar or topic-related lexis, with the effect that it might be unreasonable to cover such areas in detail, often facing boredom, lack of engagement or even offence. Thus, a much more palatable solution would be to opt for some combining form and meaning in the course of communicative activities, thus subscribing to the tenets of the focus on form approach (cf. Williams 2005). This means that attention should mainly be given to those aspects of target language proficiency which prove to be problematic, which could be accomplished by designing focused-communication tasks (i.e. such that require the use of specific linguistic features for successful completion), conducting conscious-raising and dictogloss activities (i.e. such which encourage target language use in the process of collaborative construction of linguistic knowledge) or appropriate provision of corrective feedback at the moment of meaning and message conveyance (e.g. consistent application of clarification requests to address persistent errors in the use of a specific structure). An additional advantage of such an approach is the fact that, while it allows the development of explicit knowledge about language, it also enables the application of this knowledge in more or less spontaneous language use, which might trigger the growth of the procedural, implicit knowledge necessary for real-time communication and useful in the course of the split-second decision making in the language classroom. This kind of instruction should be extended as well to the teaching of such 
sociolinguistic and discourse issues as appropriate use of various spoken and written genres (e.g. structure of narratives) or the management of turntaking mechanisms in educational discourse, with the latter relying on such techniques as analyzing transcripts and video-recordings of naturalistic and classroom interactions or developing on this basis situation-specific language. Another important area that deserves special attention are sociopragmatic and pragmalinguistic conventions that teachers fail to master because they are typically neglected in pre-service training and are difficult to acquire through exposure, even if such exposure is readily available in the ambient environment (cf. Roever 2009). An attempt should also be made to train teachers in the use of the most useful communication strategies, namely those that are based on the target language, with the caveat that also in this case teachers should be provided with the opportunity to apply their explicit knowledge (e.g. examples, specific realizations) in spontaneous language use (e.g. completing communicative tasks). When it comes to the choice of resources, it is crucial to draw upon and encourage the use of authentic materials, such as books, journals, television programs or movies, as well as the multitude of possibilities afforded by information and communication technologies, such as the Internet, educational software, electronic dictionaries and the like.

It is the conviction of the author that an integral component of language training for in-service teachers should be a comprehensive program aimed at promoting their autonomy and reflection, as this would serve the dual purpose of preparing them to improve target language competence when left to their own devices and increasing the likelihood of their instilling a similar attitude in their students. Similarly to the stage of needs analysis, this could be done, for example, by encouraging systematic self-evaluation with the assistance of the scales and descriptors in the Common European Framework as well as the checklists and other sections included a suitable model of the European Language Portfolio. In-service teachers could also be requested to keep and regularly review personal language learning diaries as a useful way of identifying their strengths and weaknesses, pinpointing recurrent problems, and coming up with most effective solutions, perhaps in cooperation with program instructors. Although this technique is likely to be met with resistance from some participants, it requires candor and self-disciplines from those willing to embrace it, and sufficient time has to be allocated to the discussion of the entries, it undoubtedly holds substantial potential in promoting independent language learning. Of paramount importance is also raising inservice teachers' awareness of efficient and inefficient ways of maintaining their target language proficiency, and this is very closely related to helping them develop a repertoire of useful language learning strategies. In other 
words, participants should be familiarized with a range of metacognitive, cognitive and socioaffective strategies (cf. O'Malley and Chamot 1990), preferably in coordination with a methodology-based module of the program, and experiment with them when performing the diverse tasks and activities intended to contribute to the development of their communicative competence. Last but not least, efforts should be made to encourage regular contact with the target language by means of the resources mentioned above, which could involve including among credit requirements the completion of individualized assignments or group projects.

Several useful recommendations can also be offered when it comes to the organization of a course or program module devoted to improving the target language competence of in-service teachers. Since, as pointed out above, such training should enable constant integration of form and meaning so that its participants have copious opportunities to apply their explicit knowledge in meaning and message conveyance, it would probably be most beneficial to opt for the weak version of a task-based syllabus in which difficulties encountered in completing communicative tasks provide an impetus for dealing with specific language points (cf. Skehan 1998). Emphasis should also be laid on reconciling general and individualized objectives by, for example, allowing time for in- and out-of-class consultations, as well as reserving ample time for performing activities of the participants' own choosing. It would also be advisable to integrate activities aimed at the development of target language skills with those intended to promote autonomy, reflection and self-evaluation by, for example, encouraging discussions of diary entries in the target language, relating the use of self-assessment grids and checklists to the completion of language tasks, and combining strategy training with the pursuit of specific linguistic goals. Although it is clearly possible to set up stand-alone courses that would solely focus on the development of inservice teachers' language proficiency, it would appear much more beneficial to organize comprehensive teacher training programs which would combine language improvement with the development of expertise in teaching methodology. In this way, it would be possible to instantaneously relate what happens in the language component to the issues discussed in the methodology component, thus facilitating transfer between the two and making it possible for participants to apply what they learn in the language module to planning lessons, reacting to errors or adjusting classroom language to learners' level. Finally, assessment of learning outcomes should mainly take the form of self-assessment with the help of the tools listed above, which does not rule out the possibility of using external measures, especially when this is expected by the participating teachers themselves. 


\section{PRACTITIONERS' CONCERNS}

Reasonable and useful as the guidelines presented in the previous section might be, they have to be pitted against the realities of different educational contexts and informed by the opinions of language teachers themselves, as it is clear that their implementation will be afflicted with numerous problems. The participants of the workshop conducted by the present author as part of the SemLang Summer University, for example, pointed to the lack of incentive for teachers to improve their target language proficiency, either in their own time or by enrolling in special training programs. Such incentives might include financial support, particularly in view of the fact that practitioners in many countries are expected to pay for the courses they attend out of their own pockets, the introduction of official regulations in this area which would make such training mandatory, or the drawing up of a set of standards that teachers could use as a yardstick for evaluating their target language competence and identifying areas in urgent need of improvement. When it comes to specific proposals, they naturally varied from one country to the next and involved creating on-line communities of teachers concerned with improving their target language skills, integrating a language component into teacher training programs, as this is often not the case in some contexts, and raising teachers' awareness by promoting professionalism and encouraging action research. There were also areas, however, where the participants of the workshop were by and large unanimous, pointing, for example, to the need to regularly engage in informal learning activities with colleagues or students (e.g. language cafes), stressing the importance of exposure to a variety of authentic materials, emphasizing the significance of life-long learning in preservice and in-service teacher training, as well as committing themselves to the dissemination of ideas about the role of language competence and promoting EU documents related to language learning.

\section{CONCLUSIONS}

Although successful language teaching requires many different types of knowledge and skills related to different areas, there is a consensus that target language proficiency is of primary significance in this respect when it comes to non-native teachers, many of whom are in danger of becoming gradually deskilled as a consequence of limited exposure, dealing with lowlevel students and paying scant attention to self-improvement. For this reason, in-service training in the domain of language competence is indispensable and it should thus be routinely included in teacher education pro- 
grams, which does not happen in some instructional contexts. As explained in the present paper, courses or course modules aimed to promote improvement in this area should best be integrated with methodology training, include both a general and an individual component, focus on all the dimensions of communicative competence, draw upon task-based methodology, encourage a simultaneous focus on form and meaning, and foster the development of practitioners' autonomy and reflection. Clearly, specific implementations of these broad guidelines are bound to vary from country to country since the nature of second language teacher education as such is inevitably a function of the specificity of a given educational context.

\section{REFERENCES}

Bachman, L.F., 1990. Fundamental Considerations in Language Testing. Oxford: Oxford University Press.

Berry, R., 1990. The Role of Language Improvement in In-Service Teacher Training: “Killing Two Birds with One Stone". In: System 18, 97-105.

Canale, M., 1983. From Communicative Competence to Communicative Language Pedagogy. In: Richards, J.C., Schmidt, R. (eds). Language and Communication. London: Longman, 2-27.

Canale, M., Swain, M., 1983. Theoretical Basis of Communicative Approaches to Second Language Testing and Teaching. In: Applied Linguistics 1, 1-47.

Ellis, R., 2009. Implicit and Explicit Learning, Knowledge and Instruction. In: Ellis, R., Loewen, S., Elder, C., Erlam, R., Philp, J., Reinders, H. (eds). Implicit and Explicit Knowledge in Second Language Learning, Teaching and Testing. Bristol: Multilingual Matters, 3-25.

Farrell, T.S.C., 2007. Reflective Language Teaching: From Research to Practice. London: Continuum.

Harmer, J., 2007. The Practice of English Language Teaching (fourth edition). Harlow: Pearson Education.

Kelly, M., Grenfell, M., Allan, L., Kriza, C., McEvoy, W., 2004. European Profile for Language Teacher Education - a Frame of Reference. Final Report. Luxemburg: European Commission.

Lafayette, R., 1993. Subject Matter Content: What Every Foreign Language Teacher Needs to Know. In: Guntermann, G. (ed.). Developing Language Teachers for a Changing World. Illinois: National Textbook Company, 124-158.

Medgyes, P., 2001. When the Teacher is a Non-Native Speaker. In: Celce-Murcia, M. (ed.). Teaching English as a Second or Foreign Language (third edition). London: Heinle \& Heinle, 429-442.

O'Malley, J.M., Chamot, A.U., 1990. Learning Strategies in Second Language Acquisition. Cambridge: Cambridge University Press.

Roberts, J., 1998. Language Teacher Education. London: Arnold.

Roever, C., 2009. Teaching and Testing Pragmatics. In: Long, M.H., Doughty, C.J. (eds). The Handbook of Language Teaching. Oxford: Wiley-Blackwell, 560-577.

Skehan, P., 2000. Task-Based Instruction: Theory, Research, Practice. In: Pulverness, A. (ed.). IATEFL 2002: York Conference Selections. Canterbury: IATEFL, 90-99.

Van Ek, J.A., 1986. Objectives of Foreign Language Learning. Vol. 1: Scope. Strasbourg: Council of Europe.

Williams, J., 2005. Form-Focused Instruction. In: Hinkel, E. (ed.). Handbook of Research in Second Language Teaching and Learning. Mahwah, NJ: Lawrence Erlbaum, 671-691. 